\title{
Control of adipogenesis by oxylipins, GPCRs and PPARs
}

Valentin Barquissau ${ }^{1,2}$, Rayane AGhandour ${ }^{3}$, Gérard Ailhaud ${ }^{3}$, Martin Klingenspor ${ }^{4}$, Dominique Langin $^{1,2,5}$, Ez-ZoubirAmri ${ }^{3}$ and Didier F Pisani ${ }^{3^{*}}$

${ }^{1}$ Inserm, UMR1048, Obesity Research Laboratory, Institute of Metabolic and Cardiovascular Diseases, Toulouse, 31432, France

${ }^{2}$ University of Toulouse, UMR1048, Paul Sabatier University, Toulouse, 31432, France

${ }^{3}$ Université Côte d'Azur, CNRS, Inserm, iBV, France

${ }^{4}$ Technische UniversitätMünchen, Chair of Molecular Nutritional Medicine, Else KrönerFresenius Center, 85350 Freising-Weihenstephan, Germany

${ }^{5}$ Toulouse University Hospitals, Department of Clinical Biochemistry, Toulouse, 31059, France

*Correspondingauthor: Dr. Didier F Pisani, iBV; Université de Nice Sophia-Antipolis, UMR7277 CNRS - UMR1091 INSERM; Faculté de Médecine; 28 Avenue de Valombrose 06107 Nice cedex 2, France; Tel: +33 4933777 07; e-mail: pisani@unice.fr 
Abstract.Oxylipins are bioactive metabolites derived from the oxygenation of $\omega 3$ and $\omega 6$ polyunsaturated fatty acids, triggered essentially by cyclooxygenase and lipoxygenase activities. Oxylipins are involved in the development and function of adipose tissue and their productions are strictly related to diet quality and quantity. Oxylipins signal via cell surface membrane (G Protein-coupled receptors) and nuclear receptors (peroxisome proliferator-activated receptors), two pathways playing a pivotal role in adipocyte biology. In this review, we made an attempt to cover the available knowledge about synthesis and molecular function of oxylipins known to modulate adipogenesis, adipocyte function and phenotype conversion, with a focus on their interaction with peroxisome proliferator-activated nuclear receptor family.

Key words.Eicosanoid; prostanoid; adipocyte; PPARa; PPARß/ס; PPARy.

Abbreviations. PUFA, polyunsaturated fatty acids; LA, linoleic acid; ARA, arachidonic acid; LNA, $\alpha$-linolenic acid; EPA, eicosapentaenoic acid; DHA, docosahexaenoic acid; DGLA, dihomo-y-linolenicacid; COX, cyclooxygenase; LOX, lipoxygenase; PG, prostaglandin; TX, thromboxane; LT, leukotriens; Rv, resolvin; WAT, white adipose tissue; BAT, brown adipose tissue; GPCR, G protein-coupled receptor; PPAR, peroxisome proliferator-activated receptor; PPRE, PPAR response element; CRE, CREB response element; UCP, uncoupling protein. 


\section{Introduction: Metabolism, fatty acids and adipose tissue development.}

Unbalanced energy homeostasis in mammals is generally due to reduction in energy expenditure aggravated by fat and carbohydrate overconsumption. High-fat diets are considered to be obesogenic as they produce a consistent increase in white fat mass that is related to the quality, quantity and the duration of the diet. However, the contribution of dietary fat quantity in increasing body weight remains controversial, as no clear correlation betweenthis increase and the amount of ingested fat has been reported $[1,2]$. This raises the possibility of a qualitative issue which is observed regarding the composition of dietary lipids at the disposal of world-wide populations, in particular those of industrialized countries. More specifically,dietary changes in the proportions of polyunsaturated fatty acids (PUFAs) of n-6 (w6) (linoleic acid, LA: 18:2 n-6; arachidonic acid, ARA: 20:4 n-6) and n-3 (w3) series ( $\alpha$-linolenic acid, LNA: 18:3 n-3; eicosapentaenoic acid, EPA: 20:5 n-3; docosahexaenoic acid, DHA: 22:6n-3) led to substantial increases in the w6/w3 PUFA ratio. PUFAs are "essential" fatty acids as they are required for normal development and their endogenous synthesisis extremely limited in humans[3]. In adult, both a high intake of $\omega 6$ LA and diets associated with a very high $\omega 6 / \omega 3$ ratios have been associated with the development of several diseases, including cardiovascular, inflammatory and autoimmune diseases, as well as cancer [4-6]. Studies have shown that mice exposed to diets with high levels of $\omega 6$ PUFA, during the perinatal period, displayed a progressive accumulation of body fat across generations[7]. This observation is in agreement with human situation as overweight and obesity increased within a given population during the last decades, and emerged earlier in life [7]. At the same time, several studies demonstrated the pivotal role of PUFA metabolites, especially ARA-derived metabolites, in fat mass increase through combination of adipocyte hyperplasia and hypertrophy of adipose tissue, as well as in decrease of energy expenditure due to inhibition of thermogenic adipocyte activity[8-10]. In addition, a meta-analysis showed that a decrease in $\omega 3$ PUFA intake can be considered as risk factor for several pathologies in humans[11]. Altogether, these data demonstrated the crucial function of PUFA metabolites in all stages of life, from development to adult life. 


\section{Origin of oxylipins.}

Fatty acids are key components of cell membranes as complex lipids, and of stored energy under the form of triglycerides. Lipase activities enable thereleaseof storedPUFAswhich are prone to undergoing oxidation reactions through both enzymatic and non-enzymatic activities to form oxygenated derivatives. Due to their potency and short half-life, these derivatives, termed oxylipins, are not stored but synthesized de novo in a tightly regulated and dynamic manner[12], keeping low the level of free PUFAs[13].Synthesis of oxylipinstakes place from developmental stages to adult life. In mammals, oxylipins can be divided into two main categories, the eicosanoids (synthesized from C20 PUFAs, i.e.ARA, EPA anddihomo-y-linolenicacid, DGLA) and the docosanoids (synthesized from C22 PUFAs, i.e.DHA). A third class of metabolites are derived directly from linoleic acid and composed of two members, 9- and 13hydroxyoctadecadienoic acids (HODEs). Oxylipins, which differ by their length and double bond configuration, are synthesized by several alternative and consecutive reactionsand display crucial signaling functions. The diversity of their functions is directly related to their structural diversity (review in [14-16]).

The two major enzymatic pathways of oxylipin precursors are triggered by cyclooxygenases (COX-1 and COX-2) and lipoxygenases (3-, 5-, 12- and 15-LOX). Depending onthe PUFA and the pathway involved, they generate prostanoids (i.e.prostaglandins, PGs; thromboxanes, TXs; prostacyclin, PGI2), leukotrienes(LTs) or resolvins (Rvs). There is a third pathway involving the enzyme cytochrome P450 epoxygenase which generates epoxides (i.e.epoxyeicosatrienoic acids, EETs) and hydroperoxydes metabolites (i.e.hydroepoxyeicosatrienoic acids, HPETEs).

Prostanoids are oxygenated derivatives of ARA, EPA and DGLA synthesized upon COX activities which catalyze the formation of a cyclopentane ring. COX-1 is permanently activated and contributes to the maintenance of physiological functions by maintaining a basal synthesis of PGs[17]. COX-2 has been identified as inducible form, especially in responseto inflammatory situation[18]. COX-1 and -2 metabolize ARA, DGLA and EPA intoPGH2, PGH1 andPGH3, respectively. These intermediate 
metabolites act as a core from which diverge different enzymatic pathways leading to the synthesis of thevarious prostanoids (PGs, PGI2 and TXs).

LTs, another eicosanoid member of the family, derive from ARA or EPA by the action of LOXs. These enzymes introduce a hydroperoxide function on positions 3, 5, 12 or 15 of the PUFAs. Their derivatives, obtained by the activity of one or several LOXs activities, include LTA, cysteinyl leukotrienes LTB, LTC and LTD, as well as lipoxins (LXA and $L x B)$, oxo-ETE, hepoxilins ( $H x A$ and $H x B$ ) and RvE series, these latter compounds arise from EPA only.Finally, DHA is also converted by LOXs which leads to the formation of several docosanoidssuch as RvD, neuroprotectins and maresins[19].

Oxylipins can activate soluble intracellular receptors or diffuse out of the cell through the plasma membrane and signal through membrane receptors in a paracrine or autocrine manner [20, 21].

\section{PPAR family: molecular view.}

Peroxisome proliferator-activated receptors (PPARs) are transcription factors belonging to the ligand-activated nuclear hormone receptor superfamily. PPARa (NR1C1) was the first subtype to be identified in the early 1990s when its ligands were found to induce peroxisome proliferation [22]. So far, two additional PPAR subtypes, PPARß/ס (NR1C3) and PPARY (NR1C2), have been discovered. At the organism level, PPARs have a wide distribution but display tissue isotype specificity [23, 24]. PPARa is mainly expressed in tissues with elevated oxidative capacities such as liver, kidney, heart, skeletal muscle or BAT. PPARß/ס (also named FAAR [25]) is widely expressed as it is found in tissues such as gastrointestinal tract, skin, heart, skeletal muscle or adipose tissues[26]. PPARy displays several isoforms among which PPARY2 is exclusively and highly expressed in adipose tissues. PPAR natural ligands are fatty acids and their metabolites derived from diet or from signaling pathways, namely oxylipins (see below, section 4).

PPARs exert their transcriptional activity after heterodimerization with retinoic $X$ receptor $(R X R)$, by binding DNA through interactions between their DNA binding domain and target sequences called PPAR response elements (PPREs). PPAR-RXR 
heterodimer activity represents a permissive transcriptional model where ligands of either receptor activate transcription of target genes, with a synergistic effect arising from binding of ligands to both receptors [23, 24]. Furthermore, PPAR transcriptional activity is also regulated by several co-activators, such as PGC-1a[27], and corepressors, such as NCoR[28]. Finally, post-translational modifications such as phosphorylation, ubiquitylation and sumoylation affect PPAR activity [28, 29]. Thus, PPAR activity is highly dependent on the complex interplay between expression level of PPAR isotypes, affinity for the promoter, ligand and cofactor availability and inputs from upstream signaling pathways [23].

In addition to direct genomic actions, PPARs also mediate indirect repressive transcriptional effects, called "transrepression", either through protein-protein interactions with transcription factors preventing them from binding their target genes or by blocking release of corepressor complexes. These mechanisms are of importance for anti-inflammatory PPAR properties [30].

PPARs are involved in crucial cellular processes ranging from cell proliferation and differentiation to inflammation and energy metabolism [23]. However, as sensors of lipid metabolites, they have a special role in regulating adipose tissue homeostasis.

PPARy is the master regulator of white and brown adipose tissue formation and function expressed at similar levels in both tissues. It is active early during adipogenesis [31] and is required for adipocyte differentiation and survival [32, 33]. Adipose tissuespecific knockout of PPARy triggers severe lipoatrophy leading to absence of white (WAT) and brown (BAT) adipose tissue in mice [34], which is consistent with its role in stimulating expression of genes required for adipocyte functions: fatty acid uptake, transport and esterification, lipogenesis, lipolysis, thermogenesis, adipokine synthesis and secretion. Beyond adipogenesis, PPARy activation in mature white adipocytes promotes white-to-brown adipocyte conversion at both molecular and functional levels [35-38].

As a major factor regulating oxidative capacities, PPARa is much more abundant in BAT compared to WAT and is expressed later in the adipogenic process compared to PPAR $\beta / \delta$ and PPARy[31]. In murine brown adipocytes, PPAR $\alpha$ controls the expression of genes involved in fatty acid oxidation as well as in the thermogenic 
programmethrough induction of PGC1 $\alpha$ and PRDM16, two coactivators driving brown adipogenesis [39-41]. However, recent findings suggest that PPARa may also have important functions in WAT as PPARa agonist treatment promotes WAT browning in wild-type mice [42]. Conversely, PPARa knockout-mice are resistant to $\beta 3$-adrenergic receptor-agonist induced browning [35]. Accordingly, in human adipocytes, PPARa activation induces expression of oxidative and brown adipocyte-specific genes, including UCP1 [35, 43, 44].

PPAR $\beta / \delta$ is expressed at similar levels in WAT and BAT [31]. Its importance in early stages of white adipogenesis relies on its capacity to regulate mitotic clonal expansion of adipocyte precursors and to induce PPARy expression [26, 45-48]. Furthermore, it has recently been shown that PPAR $\beta / \delta$ was required in brown adipocytes to reach full expression of UCP1 and thermogenic genes and to endow mice with cold protection $[40,49]$ and similarly, UCP1 expression was increased in WAT of mice overexpressing PPAR $\beta / \delta[50]$.

\section{Indirect and direct modulations of PPARs by oxylipins.}

The diversity, concentration and fate of the produced oxylipins as well as the variety of PPAR equipment of targeted cells will determine the nature of subsequent events which may explain the consistent failure to identify "true" ligands of a given PPAR. Moreover, for a given ligand acting intracellularly or from outside once secreted leads to various events. For example, prostacyclin is classically synthesized and secreted in order to activate its cognate plasma membrane receptor IP. Interestingly, prostacyclin can also signal through nuclear receptors of the producing cell, under conditions where COX-2 and the prostacyclin synthase (PGIS) co-localize in the periphery of nuclear membrane [51]. Another hypothesis, not completely proven so far, is the nuclear production of PUFA metabolites and/or their trafficking to the nucleus via cytosolicfatty acid binding proteins (FABPs). FABPs are intracellular lipid binding proteins, able to carry fatty acids from one point to another. There is some evidence that FABPs can translocate to the nucleus, where they deliver fatty acids or other hydrophobic compounds and thus favor their interaction with nuclear receptors[52, 53]. 
Oxylipins act mainly in an autocrine or paracrine manner and exert their effects through appropriate membrane receptors. These receptors are coupled to $G$ protein characterized by the associated $\alpha$ subunit allowing to activate or inhibit the production of the second messengers, $\mathrm{Ca}^{2+}$ and CAMP. Besides mediation through classic Gaq (induces calcium signaling), Gas (activates adenylate cyclase) and Gai (inhibits adenylate cyclase) subunits, it has been shown that some of the oxylipin effects could be mediated by GBy subunits, which are able to negatively control adenylate cyclase or activate some ion channels and MAPK pathways (reviewed in [54]). The receptors for ARA-derived metabolitesare well known and have been extensively studied (Figure 1). Interestingly, prostanoids and leukotrienes derived from EPA are able to activate the same receptors as ARA metabolitesbut with lower affinity [55]. Resolvin, protectin and maresin receptors are less known, excepted for ChemR23, a Gai-coupled receptor displaying a high affinity for RvE1[56].

Figure 1. Eicosanoid synthesis pathways derived from ARA and their targeted receptors.

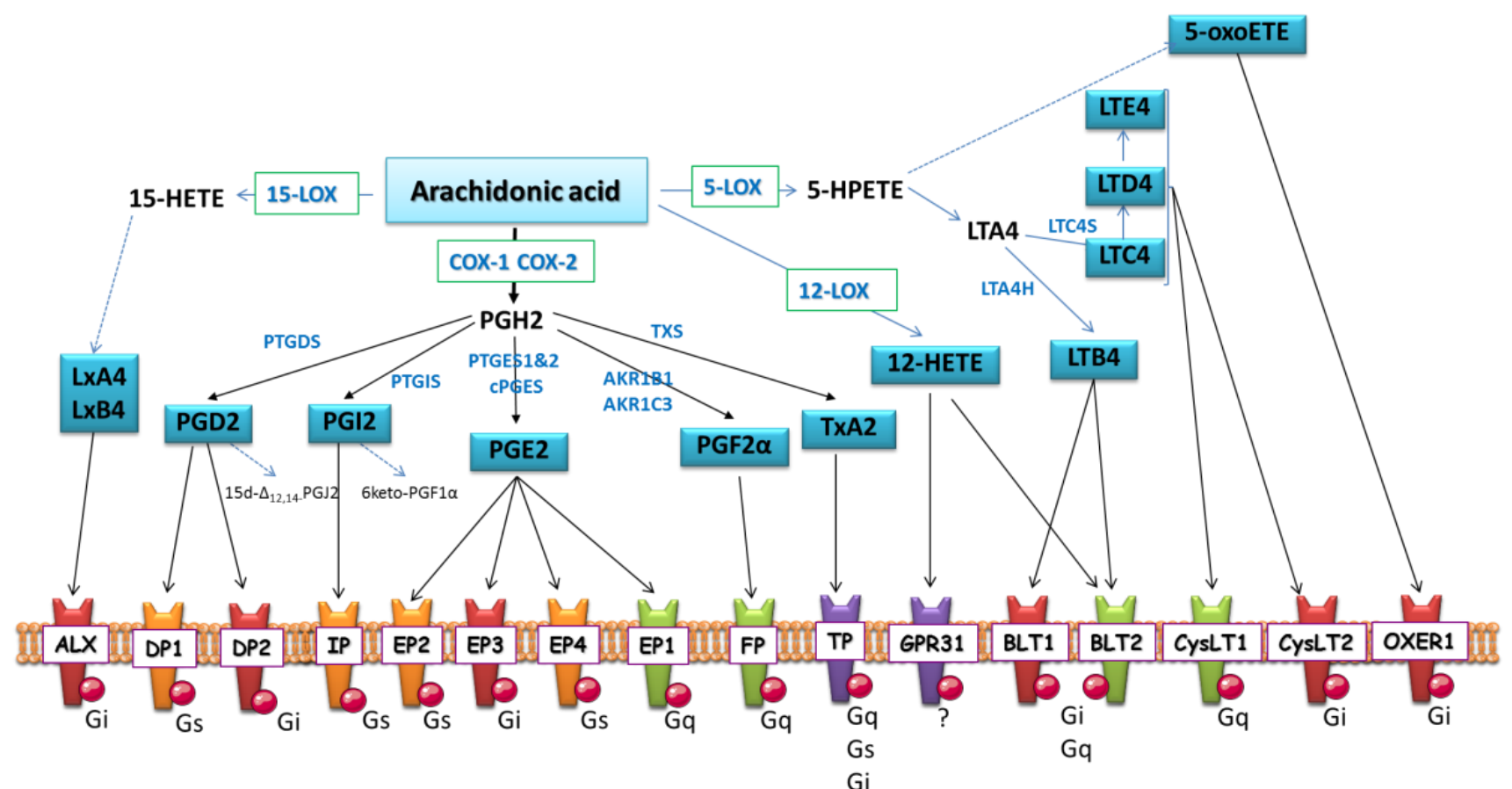

Oxylipins are able to indirectly mediate PPARs activity through the activation of these pathways. Indeed, when oxylipins activate cAMP/PKA pathway, they lead to the phosphorylation of CREB which in turn is able to 1) transactivate expression of numerous PPAR partners, such as PGC1 and C/EBP family members, or 2) synergize 
the transcriptional activity of PPARs on promotersharboring PPREs and CREs (reviewed in [57]). Moreover, CAMP mediated pathway can induce the phosphorylation of PPAR cofactors such as PGC1 $\alpha$. In an opposite manner, the inhibition of adenylate cyclaseactivity by Gai subunit disruptsthesecAMP dependent pathways.Another key pathway linking PPAR and oxylipins is the $\mathrm{Ca}^{++}$pathway. PGF2 $\alpha$ has been reported to activate $\mathrm{Ca}^{++}$signaling and to induce PPARy phosphorylation and thus its inactivation [58]. ERK1/2 signaling pathway appeared to be involved in this phenomenon in adenocarcinoma cells in which PGF2 $\alpha$, via IP/Ca ${ }^{++}$signaling, allowed phosphorylation of ERK1/2 which in turn led to PPARY degradation through the ubiquitin/proteasome pathway $[59,60]$. Other data showed that $\mathrm{Ca}^{++} /$calcineurinmediated pathway inhibits PPARy expression [61-64]. Altogether, these observations demonstrate that oxylipinmediated activation of $\mathrm{Ca}^{++}$signaling via Gaq-coupled receptors inhibits PPARs expression and activity, while oxylipin-mediated activation of cAMP signaling via Gascoupled receptors promotes PPARs expression and activity.

\begin{tabular}{|c|c|c|c|}
\hline ligands & PPAR $\alpha$ & PPAR $\beta / \delta$ & PPARY \\
\hline $\begin{array}{l}\text { PGA1 } \\
\text { PGA2 } \\
\text { PGD1 } \\
\text { PGD2 } \\
\text { LTB4 } \\
\text { 8-HETE } \\
\text { PGJ2 } \\
\text { PGI2 } \\
\text { 15d- } \Delta^{12,14-P G J 2} \\
\Delta^{12} \text {-PGJ2 } \\
\text { 15-HETE } \\
\text { 12-HETE } \\
\text { 9-HODE } \\
\text { 13-HODE } \\
\text { Hepoxilin } \\
\text { 5-oxoETE }\end{array}$ & $\begin{array}{c}\text { Yu et al. } 1995 \text { [65] } \\
\text { Yu et al. } 1995 \text { [65] } \\
\text { Yu et al. } 1995 \text { [65] } \\
\text { Yu et al. } 1995 \text { [65] } \\
\text { Devchand et al. } 1996 \text { [66] } \\
\text { Yu et al. } 1995 \text { [65] } \\
\text { Brun et al. } 1996 \text { [67] } \\
\text { Brun et al. } 1996 \text { [67] } \\
\text { Brun et al. } 1996 \text { [67] } \\
\\
\text { Delerive et al. } 2000 \text { [68] } \\
\text { Yu et al. } 2007 \text { [69] }\end{array}$ & $\begin{array}{l}\text { Brun et al. } 1996 \text { [67] } \\
\text { Brun et al. } 1996 \text { [67] } \\
\text { Naruhn et al. } 2010 \text { [70] }\end{array}$ & $\begin{array}{c}\text { Yu et al. } 1995 \text { [65] } \\
\text { Yu et al. } 1995 \text { [65] } \\
\text { Yu et al. } 1995 \text { [65] } \\
\text { Yu et al. } 1995 \text { [65] } \\
\\
\text { Forman et al. } 1995 \text { [71] } \\
\text { Brun et al. } 1996 \text { [67] } \\
\text { Forman et al. 1995[71]Kliewer et al. } 1995 \text { [72] } \\
\text { Fujimori et al. } 2012 \text { [73] } \\
\text { Huang et al. } 1999[74] \\
\text { Sun et al. } 2015 \text { [75] } \\
\text { Nagy et al. } 1998 \text { [76] } \\
\text { Huang et al. } 1999 \text { [74] } \\
\text { Hallenborg et al. } 2010[77] \\
\text { O'Flaherty et al. } 2005 \text { [78] }\end{array}$ \\
\hline
\end{tabular}

Table 1. List of the oxylipins able to bind PPARs and corresponding references. 
In addition to these indirect relationships between oxylipins and PPARs, it is well accepted that numerous PUFAs metabolites are PPAR ligands. Several studies have demonstratedthe ability of these metabolites to promote the transactivation effects of PPARa, PPAR $\beta / \delta$ and PPARy using in vitro approaches based on PPRE-reporter assays. A non-exhaustive list of these oxylipins is proposed in Table 1.

It is important to note that some of these ligands have been essentially characterized in vitro, and in vivo function remains questionable, especially with regard to the high doses used in these approaches.

\section{Interaction between PPARs, GPCRs and oxylipins in commitment and differentiation of preadipocytes.}

Earlier, it has been demonstrated that, among long chain fatty acids, ARA was the main adipogenic component of fetal bovine serum required for differentiation of cultured mouse white preadipocytes[9, 79]. These findings were obtained owing to the establishment and characterization of Ob17 preadipocyte cell line able to convert to mature adipocytes [80, 81]. Treatment of these cells with indomethacin[82], a cyclooxygenase inhibitor, as well as co-treatment with ARA [9]demonstrated the involvement of oxygenated metabolites in differentiation mechanisms.

Shortly thereafter, using Ob17 cells, the inhibitory effect of PGF2 $\alpha$ on the differentiation processwas demonstrated[83]. Thirty years later, the molecular signaling driving the anti-adipogenic effect of PGF2 $\alpha$ has been deciphered. PGF2abinds and activates the FP membrane receptor coupled to Gq subunit (Figure 2). This receptor activation triggers an intracellular $\mathrm{Ca}^{2+}$ fluxand activationof calcineurin, a phosphatase known to inhibit the expression of PPARy[63].

A second pathway has recently been described in murine 3T3-L1 preadipocytes[84]. In these cells the activation of FP receptor leads to activation of $\mathrm{Ca}^{2+} / \mathrm{PKC} / \mathrm{MAPK}$ signaling pathway. The resulting phosphorylationof ERK1/2 inducesan overexpression of Fos-related antigen-1 (Fra-1) which blocked adipogenesis through the inhibition of PPARy activity [84].This inhibitory effect of PG2a did not reflect the positive effect of ARAon adipogenesis and thusmight involveother metabolites. 
Among prostanoids,some candidatesmay explain the pro-adipogenic effect of ARA. The15d- $\Delta^{12,14}$.PGJ2, a PGD2-derived metabolite, has been characterized as a strong PPARy ligand and displayed a pro-adipogenic effect when it is used at high concentration[71][72].Prostacyclin (PGI2) is synthesized and secreted by adipocytes and is able to modulate PPARy activity directly and indirectly. Upon secretion from preadipocytes, prostacyclin was found to be active via the prostacyclin receptor (IP) present at the cell surface of preadipocytes. ARA, acting through the IP/prostacyclin pathway, triggered CAMP production and activated the pro-adipogenic protein kinase $A$ pathway [85, 86](Figure 2).

Figure 2. Schematic representation of pathways activated by ARA-derived metabolites and their impact on PPAR and thermogenic adipocyte gene expression. PPRE: PPAR response element; CRE: CREB response element; ARA: arachidonic acid; PG: prostaglandins; PGI2: prostacyclin.

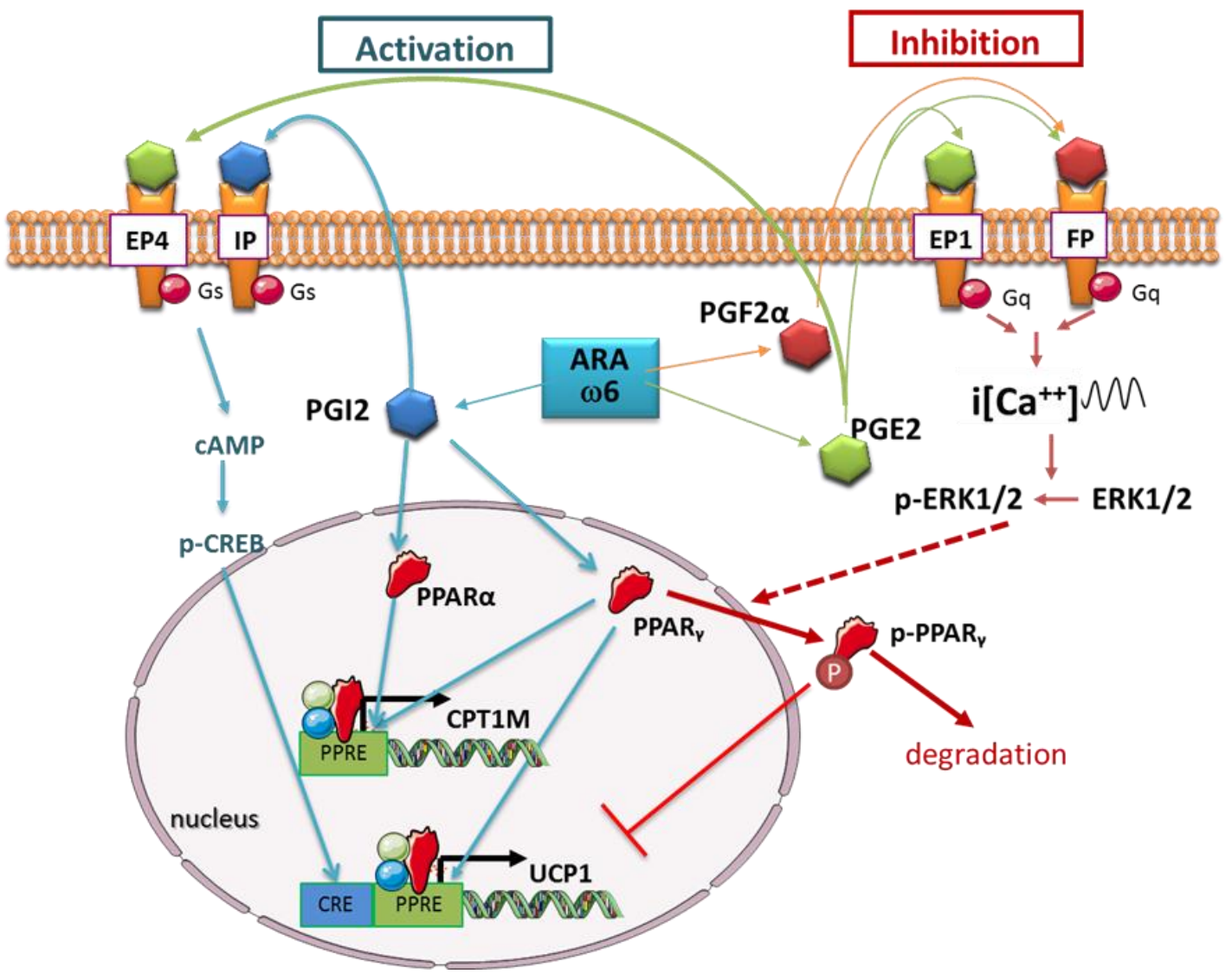

In rodents, both ex vivo and in vivo exposure of white adipose tissue to carbaprostacyclin, a stable analogue of PGI2, was able to stimulate the formation of 
adipocytes within a few hours[87]. Similar results were obtained with human preadipocytes [88]. To gain further insights into the contribution of prostacyclin signaling pathway in mouse adipose tissue development, wild-type mice and mice invalidated for IP $\left(\mathrm{ip}^{-/}\right)$were used. In contrast to wild-type mice, pups from $\mathrm{ip}^{-/}$mice showed no gain in body weight or in fat mass when fed a LA-enriched diet (LA/LNA ratio of 30) compared to thebalanced LA/LNA diet (ratio of 4)[9]. Last but not least, carbaprostacyclin (cPGI2), a stable analog of prostacyclin, is able to bind to PPARs. When cPGI2 activated PPARY and PPARa, but not PPARß/Y, it promoted adipogenesis [67]. Like for $15 d-\Delta^{12,14}$.PGJ2, the data about CPGI2 are convincing but did not demonstrate that the ARA positive effect on adipogenesis is triggered by this prostanoid.Other PUFAs derived metabolites such as 9- and 13-HODE,first identified in macrophages, have been described to bind to PPARy in adipocytes [76] and to be involved in adipogenesis [89]. Nevertheless, none of these fatty acid metabolites has been demonstratedto accumulate strikingly during the early steps of adipocytedifferentiation and thus might not be considered as physiological ligands.

PGE2 controls many aspects of adipocyte differentiation. This prostaglandin activates one or more of its cognate receptors (EP1, EP2, EP3, and EP4) in a dosedependent manner [90]. This allows the induction of different intracellular signals; EP2 and EP4 have the highest affinity for PGE2 and are coupled to Gas protein, while EP3 receptor is coupled to Gaiand EP1, which has the lowest affinity for PGE2, is coupled to Gaq proteins. Thus the effects of PGE2 on adipogenesis remain various and opposed as they are strictly related to its concentration and the expression of its receptors [91]. For example, in preadipocytes, PGE2 activates the EP2 and EP4 receptors and induces PKA pathway to initiate adipogenesis [92]. Conversely, a crucial involvement of mPGES1 (microsomal PGE2 synthase 1) is observed in adipogenesis. PGE2 suppressed PPARy expression and blocked rosiglitazone-induced preadipocyte differentiation. Consistently, pharmacological mPGES-1 inhibition promotes this differentiation[93].

Among leukotriene family, LTB4 has been characterized as a PPARa ligand promoting lipid accumulation in differentiating adipocytes[94]. It is interesting to note that 
LTB4 signals through two membrane receptors, BLT1 and BLT2 that are linked to Gaq and Gai proteins, two well-known pathways endowed with anti-adipogenic activity.

Finally, hepoxilin A3 and B3 (HxA3 and HxB3), a family of metabolites generated from ARA by the sequential activities of ALOX12 and ALOX3 (or epidermis LOX3),represent potential candidates to explain ARA effect on adipogenesis. Indeed, HxA3 and HxB3 are PPARy ligands that accumulate in the cells in the beginning of adipocyte differentiation, and they induce a strong pro-adipogenic effect[77]. Interestingly, ALOX3 is co-localized with PPARY in the nucleus of the cells, which is in accordance with a nuclear function of its metabolites. Finally, ALOX3 inhibition disrupted adipogenesis and PPARY activity.Further studies are requested to validate these results especially in human models, as they are only described in mouse 3T3-L1 preadipocytes $[77,95]$.

PUFAs metabolites can be either pro- or anti-adipogenic depending on the activation level of the CAMP pathway[96]. In 3T3-L1 preadipocytes, ARA produced a pro-adipogenic effect by a transient raise of cAMP levels. By contrast, if the cAMP pathway is already activated, there is an increased synthesis of anti-adipogenic PGs, such as PGE2 and PGF2a[96]. This situation can be observed in vivo in case of a high protein diet or in a situation of chronic inflammation [96, 97].In conclusion, the control of adipocyte differentiation by PUFAs metabolites is complex and depends on several environmental factors.

\section{Interaction between PPARs, GPCRs and oxylipins in adipocyte function.}

In addition to the control in early stepsof adipogenesis, oxylipins are known to modulate adipocyte function (lipogenesis, lipolysis, secretion...) and, more recently, phenotypic conversion such as browning or whitening processes. As adipocyte functionsare sensitive to CAMP- and $\mathrm{Ca}^{++}$-mediated pathways, modulations are mainly due to activation of membrane GPCRs by oxylipins. Differently, phenotypic conversion is transcriptionally controlled and thus involves preferentially oxylipins that are able to activate nuclear receptors such as PPARs. 
Early, the DGLA derived prostanoid PGE1 has been described as an antilipolyticagent in various species [98]. PGE2 displayed the same properties on lipolysis[99], most likely through the same receptor EP3 known to inhibit cAMP mediated pathways induced by lipolytic agents[100].Thus, inhibition of lipolysis seems to be specific to Gai-coupled receptor as PGF2a, which activates Gaq-coupled receptor, is unable to inhibit lipolysis induced by norepinephrine [101].Lipolysis is under the control of cAMPlevelsand downstream events, as well as cGMP levels in some situations[102], thus oxylipins able to bind to Gas-coupled receptorsshall be considered as potential lipolytic agents. This observation has been validated for prostacyclin[92], whichpotentiates the effect of norepinephrine on lipolysis[103].The oxylipin-mediated restriction of lipolysis seems to be a preponderant eventin vivo, as recent data demonstrate that inhibition of COX activity by indomethacin favored lipolysis under fasting condition [8, 104].

The involvement of oxylipins specifically in lipogenesis and fatty acid storage is difficult to assess, as these anabolic processes are tightly associated to adipocyte differentiation. Nevertheless, acute treatment of 3T3-L1 adipocytes demonstrated that PGE2 and PGF2 $\alpha$ might be considered as anti-lipogenic agents, likely viathe activation of EP1 and FP Gaq-coupled receptors [105]. Differently, it has been shownthat the dehydrated metabolites of PGJ2, $\Delta^{12}$-PGJ2 and 15d- $\Delta^{12,14}$.PGJ2 were able to favor lipid accumulation in adipocytesthrough direct interaction with PPARY $[106,107]$.

In adipocytes, the relationships between oxylipins and inflammation are very important. In this way, oxylipins are able to control and in return to be controlled by inflammatory cytokines. It is commonly accepted that w6-PUFA-derived metabolites induce and sustaininflammation and that $\omega 3$-PUFA-derived metabolites are protectiveor resolve inflammation (reviewed in [108]), especially viatheir PPAR ligand function (reviewed in [109]). For example, LOX-derived metabolites are involved in chemoattraction of macrophages by the autocrine stimulation of MCP-1 secretion by adipocytes[110, 111]. In addition to the control of inflammatory cytokine secretion, oxylipins are able to modulate secretion of adipokines. Indeed, it has been reported that PGD2-derived metabolites are able to inhibit leptin secretion [112], whereas PGE2 stimulates its secretion[113]. 


\section{Interactions between oxylipins and the different types of adipocytes}

White adipocytes are storing energy under the form of triglycerides whereas brown adipocytes dissipate energy from triglycerides by producing heat. These adipocytes are able to adapt their phenotype to specific situations. It is now accepted that white adipocytes can be phenotypically converted into thermogenic adipocytes (brite/beige adipocyte conversion) or in milk-producing epithelial cells (pink adipocyte conversion) (reviewed in [114]). These conversions are reversible and occur in situations where the genuine functional cells cannot assume their functions (brown adipocyte in chronic cold exposure) or along specific physiological situations (after pregnancy).So far, no data are available about involvement of oxygenated metabolites in white topink adipocyte conversion. Otherwise, several studies demonstrated the involvement of oxylipins in white to brite adipocyte conversion. Eicosanoids derived from $\omega 6$ PUFA inhibit brite adipocyte formation, in vitro and in vivo[10]. ARA inhibited the expression and function of UCP1 and these effects were mediated via cyclooxygenase activities leading to increased synthesis and release of PGE2 and PGF2 $\alpha$. Thorough analysis of the role of PGE2 and PGF2 $\alpha$ demonstrated that an oscillatory calcium pathway, due respectively to EP1 and FP receptor activation, was responsible of impairing the browning process. The sustained $[\mathrm{Ca}++]$ oscillations led in turn to the inhibition of the expression of PPARY target genes, including UCP1 gene, and suggest a broader inhibitory effect of prostaglandin-mediated pathways via the modulation of PPARY activity [10].Moreover, it has been demonstrated that $\mathrm{CPGI} 2$ was able to induce recruitment of brite adipocytes by promotingthe differentiation of progenitor cells and the conversion of white into brite adipocytes $[115,116]$. The differentiation into brite adipocytes is dependent on the IP receptor and might involve reorganization of the cytoskeleton and/or chromatin $[116,117]$. Similarly, PGE2 is able,through the activation of EP4, to promote white to brite adipocyte conversion $[10,118]$.

Interestingly, in vivo, COX pathway has been shown to be crucial for the induction of brite adipocytes formation in 129Sv mice (a strain resistant to obesity due to a high content of brown and brite adipocytes) [116, 118], but an opposite role of the same 
pathway has been recently described in C57BL/6 mice (a strain prone to develop obesity through high fat diets) [8]. In this latter case, when mice were fed a high fat diet, the inhibition of COX activities with indomethacin prevented body weight gain, partly due to enhanced recruitment of brite adipocytes in subcutaneous WAT. These results demonstrate, once again, the complexity of the oxylipin effects depending on the physiological situation.

\section{Conclusion}

In aggregate, oxylipins display a multiplicity of effects in adipocyte from the control of its differentiation to its function through the activation of two families of receptors: namely GPCRand PPAR families. In mammals, as oxylipins govern a large part of adipose tissue biology, any dysregulation in their levels may disrupt tissue homeostasis. Thus the nutritional control of their production, especially by an optimal qualitative and quantitative dietary PUFA supply, is of utmost interest in the prevention of metabolic disorders.

\section{Acknowledgments}

This work was supported by CNRS, Inserm, University Côte d'Azur, ANR PRCI-2015-01 (Nutribrite) and Nutricia Research Foundation (2015-26).

\section{Authors declare no conflict of interest.}




\section{References.}

[1] R.P. Troiano, R.R. Briefel, M.D. Carroll, K. Bialostosky, Energy and fat intakes of children and adolescents in the united states: data from the national health and nutrition examination surveys, Am. J. Clin. Nutr., 72 (2000) 1343S-1353S.

[2] W.C. Willett, R.L. Leibel, Dietary fat is not a major determinant of body fat, Am. J. Med., 113 Suppl 9B (2002) 47S-59S.

[3] M. Plourde, S.C. Cunnane, Extremely limited synthesis of long chain polyunsaturates in adults: implications for their dietary essentiality and use as supplements, Appl Physiol Nutr Metab, 32 (2007) 619-634.

[4] H. Okuyama, Y. Ichikawa, Y. Sun, T. Hamazaki, W.E. Lands, Cancers common in the USA are stimulated by omega 6 fatty acids and large amounts of animal fats, but suppressed by omega 3 fatty acids and cholesterol, World Rev. Nutr. Diet., 96 (2007) 143-149.

[5] H. Okuyama, Y. Ichikawa, Y. Sun, T. Hamazaki, W.E. Lands, Mechanisms by which dietary fats affect coronary heart disease mortality, World Rev. Nutr. Diet., 96 (2007) 119-141.

[6] A.P. Simopoulos, The importance of the ratio of omega-6/omega-3 essential fatty acids, Biomed. Pharmacother., 56 (2002) 365-379.

[7] F. Massiera, P. Barbry, P. Guesnet, A. Joly, S. Luquet, C. Moreilhon-Brest, T. Mohsen-Kanson, E.Z. Amri, G. Ailhaud, A Western-like fat diet is sufficient to induce a gradual enhancement in fat mass over generations, J. Lipid Res., 51 (2010) 2352-2361.

[8] E. Fjaere, U.L. Aune, K. Roen, A.H. Keenan, T. Ma, K. Borkowski, D.M. Kristensen, G.W. Novotny, T. Mandrup-Poulsen, B.D. Hudson, G. Milligan, Y. Xi, J.W. Newman, F.G. Haj, B. Liaset, K. Kristiansen, L. Madsen, Indomethacin Treatment Prevents High Fat Diet-induced Obesity and Insulin Resistance but Not Glucose Intolerance in C57BL/6J Mice, J. Biol. Chem., 289 (2014) 16032-16045.

[9] F. Massiera, P. Saint-Marc, J. Seydoux, T. Murata, T. Kobayashi, S. Narumiya, P. Guesnet, E.Z. Amri, R. Negrel, G. Ailhaud, Arachidonic acid and prostacyclin signaling promote adipose tissue development: a human health concern?, J. Lipid Res., 44 (2003) 271-279.

[10] D.F. Pisani, R.A. Ghandour, G.E. Beranger, P. Le Faouder, J.C. Chambard, M. Giroud, A. Vegiopoulos, M. Djedaini, J. Bertrand-Michel, M. Tauc, S. Herzig, D. Langin, G. Ailhaud, C. Duranton, E.Z. Amri, The omega6-fatty acid, arachidonic acid, regulates the conversion of white to brite adipocyte through a prostaglandin/calcium mediated pathway, Molecular metabolism, 3 (2014) 834-847.

[11] G.C. Chen, J. Yang, M. Eggersdorfer, W. Zhang, L.Q. Qin, N-3 long-chain polyunsaturated fatty acids and risk of all-cause mortality among general populations: a meta-analysis, Sci. Rep., 6 (2016) 28165.

[12] C.D. Funk, Prostaglandins and leukotrienes: advances in eicosanoid biology, Science, 294 (2001) 1871-1875.

[13] G. Perez-Chacon, A.M. Astudillo, D. Balgoma, M.A. Balboa, J. Balsinde, Control of free arachidonic acid levels by phospholipases A2 and lysophospholipid acyltransferases, Biochim. Biophys. Acta, 1791 (2009) 1103-1113.

[14] M. Barbosa, P. Valentao, P.B. Andrade, Biologically Active Oxylipins from Enzymatic and Nonenzymatic Routes in Macroalgae, Mar. Drugs, 14 (2016) 23.

[15] B.E. Tourdot, I. Ahmed, M. Holinstat, The emerging role of oxylipins in thrombosis and diabetes, Front. Pharmacol., 4 (2014) 176.

[16] M. Gabbs, S. Leng, J.G. Devassy, M. Monirujjaman, H.M. Aukema, Advances in Our Understanding of Oxylipins Derived from Dietary PUFAs, Adv Nutr, 6 (2015) 513-540.

[17] H.W. Cook, W.E. Lands, Mechanism for suppression of cellular biosynthesis of prostaglandins, Nature, 260 (1976) 630-632. 
[18] M.K. O'Banion, V.D. Winn, D.A. Young, cDNA cloning and functional activity of a glucocorticoidregulated inflammatory cyclooxygenase, Proc. Natl. Acad. Sci. U. S. A., 89 (1992) 4888-4892.

[19] C.N. Serhan, J. Dalli, R.A. Colas, J.W. Winkler, N. Chiang, Protectins and maresins: New pro-resolving families of mediators in acute inflammation and resolution bioactive metabolome, Biochim. Biophys. Acta, 1851 (2015) 397-413.

[20] G.C. Shearer, J.W. Newman, Impact of circulating esterified eicosanoids and other oxylipins on endothelial function, Curr Atheroscler Rep, 11 (2009) 403-410.

[21] W. Wahli, L. Michalik, PPARs at the crossroads of lipid signaling and inflammation, Trends Endocrinol. Metab., 23 (2012) 351-363.

[22] I. Issemann, S. Green, Activation of a member of the steroid hormone receptor superfamily by peroxisome proliferators, Nature, 347 (1990) 645-650.

[23] J.N. Feige, L. Gelman, L. Michalik, B. Desvergne, W. Wahli, From molecular action to physiological outputs: peroxisome proliferator-activated receptors are nuclear receptors at the crossroads of key cellular functions, Prog. Lipid Res., 45 (2006) 120-159.

[24] C. Christodoulides, A. Vidal-Puig, PPARs and adipocyte function, Mol. Cell. Endocrinol., 318 (2010) 61-68.

[25] E.Z. Amri, F. Bonino, G. Ailhaud, N.A. Abumrad, P.A. Grimaldi, Cloning of a protein that mediates transcriptional effects of fatty acids in preadipocytes. Homology to peroxisome proliferator-activated receptors, J. Biol. Chem., 270 (1995) 2367-2371.

[26] J.G. Neels, P.A. Grimaldi, Physiological functions of peroxisome proliferator-activated receptor beta, Physiol. Rev., 94 (2014) 795-858.

[27] P. Puigserver, Z. Wu, C.W. Park, R. Graves, M. Wright, B.M. Spiegelman, A cold-inducible coactivator of nuclear receptors linked to adaptive thermogenesis, Cell, 92 (1998) 829-839.

[28] T.B. Stanley, L.M. Leesnitzer, V.G. Montana, C.M. Galardi, M.H. Lambert, J.A. Holt, H.E. Xu, L.B. Moore, S.G. Blanchard, J.B. Stimmel, Subtype specific effects of peroxisome proliferator-activated receptor ligands on corepressor affinity, Biochemistry, 42 (2003) 9278-9287.

[29] O. van Beekum, V. Fleskens, E. Kalkhoven, Posttranslational modifications of PPAR-gamma: finetuning the metabolic master regulator, Obesity (Silver Spring), 17 (2009) 213-219.

[30] M. Ricote, C.K. Glass, PPARs and molecular mechanisms of transrepression, Biochim. Biophys. Acta, 1771 (2007) 926-935.

[31] A. Valmaseda, M.C. Carmona, M.J. Barbera, O. Vinas, T. Mampel, R. Iglesias, F. Villarroya, M. Giralt, Opposite regulation of PPAR-alpha and -gamma gene expression by both their ligands and retinoic acid in brown adipocytes, Mol. Cell. Endocrinol., 154 (1999) 101-109.

[32] E.D. Rosen, C.J. Walkey, P. Puigserver, B.M. Spiegelman, Transcriptional regulation of adipogenesis, Genes Dev., 14 (2000) 1293-1307.

[33] T. Imai, R. Takakuwa, S. Marchand, E. Dentz, J.M. Bornert, N. Messaddeq, O. Wendling, M. Mark, B. Desvergne, W. Wahli, P. Chambon, D. Metzger, Peroxisome proliferator-activated receptor gamma is required in mature white and brown adipocytes for their survival in the mouse, Proc. Natl. Acad. Sci. U. S. A., 101 (2004) 4543-4547.

[34] F. Wang, S.E. Mullican, J.R. DiSpirito, L.C. Peed, M.A. Lazar, Lipoatrophy and severe metabolic disturbance in mice with fat-specific deletion of PPARgamma, Proc. Natl. Acad. Sci. U. S. A., 110 (2013) 18656-18661.

[35] V. Barquissau, D. Beuzelin, D.F. Pisani, G.E. Beranger, A. Mairal, A. Montagner, B. Roussel, G. Tavernier, M.A. Marques, C. Moro, H. Guillou, E.Z. Amri, D. Langin, White-to-brite conversion in human adipocytes promotes metabolic reprogramming towards fatty acid anabolic and catabolic pathways, Molecular metabolism, (2016).

[36] C. Elabd, A. Basillais, H. Beaupied, V. Breuil, N. Wagner, M. Scheideler, L.E. Zaragosi, F. Massiera, E. Lemichez, Z. Trajanoski, G. Carle, L. Euller-Ziegler, G. Ailhaud, C.L. Benhamou, C. Dani, E.Z. Amri, Oxytocin 
controls differentiation of human mesenchymal stem cells and reverses osteoporosis, Stem Cells, 26 (2008) 2399-2407.

[37] A. Loft, I. Forss, M.S. Siersbaek, S.F. Schmidt, A.S. Larsen, J.G. Madsen, D.F. Pisani, R. Nielsen, M.M. Aagaard, A. Mathison, M.J. Neville, R. Urrutia, F. Karpe, E.Z. Amri, S. Mandrup, Browning of human adipocytes requires KLF11 and reprogramming of PPARgamma superenhancers, Genes Dev., 29 (2015) 722.

[38] D.F. Pisani, M. Djedaini, G.E. Beranger, C. Elabd, M. Scheideler, G. Ailhaud, E.Z. Amri, Differentiation of Human Adipose-Derived Stem Cells into "Brite" (Brown-in-White) Adipocytes, Front. Endocrinol. (Lausanne), 2 (2011) 87.

[39] E. Hondares, M. Rosell, J. Diaz-Delfin, Y. Olmos, M. Monsalve, R. Iglesias, F. Villarroya, M. Giralt, Peroxisome proliferator-activated receptor alpha (PPARalpha) induces PPARgamma coactivator 1alpha (PGC-1alpha) gene expression and contributes to thermogenic activation of brown fat: involvement of PRDM16, J. Biol. Chem., 286 (2011) 43112-43122.

[40] E.P. Mottillo, A.E. Bloch, T. Leff, J.G. Granneman, Lipolytic products activate peroxisome proliferatoractivated receptor (PPAR) alpha and delta in brown adipocytes to match fatty acid oxidation with supply, J. Biol. Chem., 287 (2012) 25038-25048.

[41] C. Tiraby, G. Tavernier, C. Lefort, D. Larrouy, F. Bouillaud, D. Ricquier, D. Langin, Acquirement of brown fat cell features by human white adipocytes, J. Biol. Chem., 278 (2003) 33370-33376.

[42] T.L. Rachid, A. Penna-de-Carvalho, I. Bringhenti, M.B. Aguila, C.A. Mandarim-de-Lacerda, V. SouzaMello, Fenofibrate (PPARalpha agonist) induces beige cell formation in subcutaneous white adipose tissue from diet-induced male obese mice, Mol. Cell. Endocrinol., 402 (2015) 86-94.

[43] A. Mazzucotelli, N. Viguerie, C. Tiraby, J.S. Annicotte, A. Mairal, E. Klimcakova, E. Lepin, P. Delmar, S. Dejean, G. Tavernier, C. Lefort, J. Hidalgo, T. Pineau, L. Fajas, K. Clement, D. Langin, The transcriptional coactivator peroxisome proliferator activated receptor (PPAR)gamma coactivator-1 alpha and the nuclear receptor PPAR alpha control the expression of glycerol kinase and metabolism genes independently of PPAR gamma activation in human white adipocytes, Diabetes, 56 (2007) 2467-2475.

[44] C. Ribet, E. Montastier, C. Valle, V. Bezaire, A. Mazzucotelli, A. Mairal, N. Viguerie, D. Langin, Peroxisome proliferator-activated receptor-alpha control of lipid and glucose metabolism in human white adipocytes, Endocrinology, 151 (2010) 123-133.

[45] J.B. Hansen, H. Zhang, T.H. Rasmussen, R.K. Petersen, E.N. Flindt, K. Kristiansen, Peroxisome proliferator-activated receptor delta (PPARdelta )-mediated regulation of preadipocyte proliferation and gene expression is dependent on cAMP signaling, J. Biol. Chem., 276 (2001) 3175-3182.

[46] C. Jehl-Pietri, C. Bastie, I. Gillot, S. Luquet, P.A. Grimaldi, Peroxisome-proliferator-activated receptor delta mediates the effects of long-chain fatty acids on post-confluent cell proliferation, Biochem. J., 350 Pt 1 (2000) 93-98.

[47] C. Bastie, D. Holst, D. Gaillard, C. Jehl-Pietri, P.A. Grimaldi, Expression of peroxisome proliferatoractivated receptor PPARdelta promotes induction of PPARgamma and adipocyte differentiation in 3T3C2 fibroblasts, J. Biol. Chem., 274 (1999) 21920-21925.

[48] C. Bastie, S. Luquet, D. Holst, C. Jehl-Pietri, P.A. Grimaldi, Alterations of peroxisome proliferatoractivated receptor delta activity affect fatty acid-controlled adipose differentiation, J. Biol. Chem., 275 (2000) 38768-38773.

[49] D. Pan, M. Fujimoto, A. Lopes, Y.X. Wang, Twist-1 is a PPARdelta-inducible, negative-feedback regulator of PGC-1alpha in brown fat metabolism, Cell, 137 (2009) 73-86.

[50] Y.X. Wang, C.H. Lee, S. Tiep, R.T. Yu, J. Ham, H. Kang, R.M. Evans, Peroxisome-proliferator-activated receptor delta activates fat metabolism to prevent obesity, Cell, 113 (2003) 159-170.

[51] H. Lim, S.K. Dey, A novel pathway of prostacyclin signaling-hanging out with nuclear receptors, Endocrinology, 143 (2002) 3207-3210. 
[52] M.L. Hughes, B. Liu, M.L. Halls, K.M. Wagstaff, R. Patil, T. Velkov, D.A. Jans, N.W. Bunnett, M.J. Scanlon, C.J. Porter, Fatty Acid-binding Proteins 1 and 2 Differentially Modulate the Activation of Peroxisome Proliferator-activated Receptor alpha in a Ligand-selective Manner, J. Biol. Chem., 290 (2015) 13895-13906.

[53] M. Kaczocha, S. Vivieca, J. Sun, S.T. Glaser, D.G. Deutsch, Fatty acid-binding proteins transport Nacylethanolamines to nuclear receptors and are targets of endocannabinoid transport inhibitors, J. Biol. Chem., 287 (2012) 3415-3424.

[54] A. Stewart, R.A. Fisher, Introduction: G Protein-coupled Receptors and RGS Proteins, Prog. Mol. Biol. Transl. Sci., 133 (2015) 1-11.

[55] M. Wada, C.J. DeLong, Y.H. Hong, C.J. Rieke, I. Song, R.S. Sidhu, C. Yuan, M. Warnock, A.H. Schmaier, C. Yokoyama, E.M. Smyth, S.J. Wilson, G.A. FitzGerald, R.M. Garavito, X. Sui de, J.W. Regan, W.L. Smith, Enzymes and receptors of prostaglandin pathways with arachidonic acid-derived versus eicosapentaenoic acid-derived substrates and products, J. Biol. Chem., 282 (2007) 22254-22266.

[56] M. Arita, F. Bianchini, J. Aliberti, A. Sher, N. Chiang, S. Hong, R. Yang, N.A. Petasis, C.N. Serhan, Stereochemical assignment, antiinflammatory properties, and receptor for the omega-3 lipid mediator resolvin E1, J. Exp. Med., 201 (2005) 713-722.

[57] M. Rogne, K. Tasken, Compartmentalization of cAMP signaling in adipogenesis, lipogenesis, and lipolysis, Horm. Metab. Res., 46 (2014) 833-840.

[58] M.J. Reginato, S.L. Krakow, S.T. Bailey, M.A. Lazar, Prostaglandins promote and block adipogenesis through opposing effects on peroxisome proliferator-activated receptor gamma, J. Biol. Chem., 273 (1998) 1855-1858.

[59] Z.E. Floyd, J.M. Stephens, Interferon-gamma-mediated activation and ubiquitin-proteasomedependent degradation of PPARgamma in adipocytes, J. Biol. Chem., 277 (2002) 4062-4068.

[60] H.N. Jabbour, K.J. Sales, S.C. Boddy, R.A. Anderson, A.R. Williams, A positive feedback loop that regulates cyclooxygenase-2 expression and prostaglandin F2alpha synthesis via the F-series-prostanoid receptor and extracellular signal-regulated kinase 1/2 signaling pathway, Endocrinology, 146 (2005) 4657-4664.

[61] Y.Y. Chen, M.H. Lee, C.C. Hsu, C.L. Wei, Y.C. Tsai, Methyl cinnamate inhibits adipocyte differentiation via activation of the CaMKK2-AMPK pathway in 3T3-L1 preadipocytes, J. Agric. Food Chem., 60 (2012) 955-963.

[62] K. Fujimori, T. Ueno, N. Nagata, K. Kashiwagi, K. Aritake, F. Amano, Y. Urade, Suppression of adipocyte differentiation by aldo-keto reductase 1B3 acting as prostaglandin F2alpha synthase, J. Biol. Chem., 285 (2010) 8880-8886.

[63] L. Liu, N.A. Clipstone, Prostaglandin F2alpha inhibits adipocyte differentiation via a G alpha qcalcium-calcineurin-dependent signaling pathway, J. Cell. Biochem., 100 (2007) 161-173.

[64] J.W. Neal, N.A. Clipstone, Calcineurin mediates the calcium-dependent inhibition of adipocyte differentiation in 3T3-L1 cells, J. Biol. Chem., 277 (2002) 49776-49781.

[65] K. Yu, W. Bayona, C.B. Kallen, H.P. Harding, C.P. Ravera, G. McMahon, M. Brown, M.A. Lazar, Differential activation of peroxisome proliferator-activated receptors by eicosanoids, J. Biol. Chem., 270 (1995) 23975-23983.

[66] P.R. Devchand, H. Keller, J.M. Peters, M. Vazquez, F.J. Gonzalez, W. Wahli, The PPARalphaleukotriene B4 pathway to inflammation control, Nature, 384 (1996) 39-43.

[67] R.P. Brun, P. Tontonoz, B.M. Forman, R. Ellis, J. Chen, R.M. Evans, B.M. Spiegelman, Differential activation of adipogenesis by multiple PPAR isoforms, Genes Dev., 10 (1996) 974-984.

[68] P. Delerive, C. Furman, E. Teissier, J. Fruchart, P. Duriez, B. Staels, Oxidized phospholipids activate PPARalpha in a phospholipase A2-dependent manner, FEBS Lett., 471 (2000) 34-38.

[69] Z. Yu, C. Schneider, W.E. Boeglin, A.R. Brash, Epidermal lipoxygenase products of the hepoxilin pathway selectively activate the nuclear receptor PPARalpha, Lipids, 42 (2007) 491-497. 
[70] S. Naruhn, W. Meissner, T. Adhikary, K. Kaddatz, T. Klein, B. Watzer, S. Muller-Brusselbach, R. Muller, 15-hydroxyeicosatetraenoic acid is a preferential peroxisome proliferator-activated receptor beta/delta agonist, Mol. Pharmacol., 77 (2010) 171-184.

[71] B.M. Forman, P. Tontonoz, J. Chen, R.P. Brun, B.M. Spiegelman, R.M. Evans, 15-Deoxy-delta 12, 14prostaglandin $\mathrm{J} 2$ is a ligand for the adipocyte determination factor PPAR gamma, Cell, 83 (1995) 803-812. [72] S.A. Kliewer, J.M. Lenhard, T.M. Willson, I. Patel, D.C. Morris, J.M. Lehmann, A prostaglandin J2 metabolite binds peroxisome proliferator-activated receptor gamma and promotes adipocyte differentiation, Cell, 83 (1995) 813-819.

[73] K. Fujimori, T. Maruyama, S. Kamauchi, Y. Urade, Activation of adipogenesis by lipocalin-type prostaglandin D synthase-generated Delta(1)(2)-PGJ(2) acting through PPARgamma-dependent and independent pathways, Gene, 505 (2012) 46-52.

[74] J.T. Huang, J.S. Welch, M. Ricote, C.J. Binder, T.M. Willson, C. Kelly, J.L. Witztum, C.D. Funk, D. Conrad, C.K. Glass, Interleukin-4-dependent production of PPAR-gamma ligands in macrophages by 12/15-lipoxygenase, Nature, 400 (1999) 378-382.

[75] L. Sun, Y.W. Xu, J. Han, H. Liang, N. Wang, Y. Cheng, 12/15-Lipoxygenase metabolites of arachidonic acid activate PPARgamma: a possible neuroprotective effect in ischemic brain, J. Lipid Res., 56 (2015) 502-514.

[76] L. Nagy, P. Tontonoz, J.G. Alvarez, H. Chen, R.M. Evans, Oxidized LDL regulates macrophage gene expression through ligand activation of PPARgamma, Cell, 93 (1998) 229-240.

[77] P. Hallenborg, C. Jorgensen, R.K. Petersen, S. Feddersen, P. Araujo, P. Markt, T. Langer, G. Furstenberger, P. Krieg, A. Koppen, E. Kalkhoven, L. Madsen, K. Kristiansen, Epidermis-type lipoxygenase 3 regulates adipocyte differentiation and peroxisome proliferator-activated receptor gamma activity, Mol. Cell. Biol., 30 (2010) 4077-4091.

[78] J.T. O'Flaherty, L.C. Rogers, C.M. Paumi, R.R. Hantgan, L.R. Thomas, C.E. Clay, K. High, Y.Q. Chen, M.C. Willingham, P.K. Smitherman, T.E. Kute, A. Rao, S.D. Cramer, C.S. Morrow, 5-Oxo-ETE analogs and the proliferation of cancer cells, Biochim. Biophys. Acta, 1736 (2005) 228-236.

[79] D. Gaillard, R. Negrel, M. Lagarde, G. Ailhaud, Requirement and role of arachidonic acid in the differentiation of pre-adipose cells, Biochem. J., 257 (1989) 389-397.

[80] P. Grimaldi, R. Negrel, J.P. Vincent, G. Ailhaud, Differentiation of ob 17 preadipocytes to adipocytes. Effect of insulin on the levels of insulin receptors and on the transport of alpha-aminoisobutyrate, J. Biol. Chem., 254 (1979) 6849-6852.

[81] R. Negrel, P. Grimaldi, G. Ailhaud, Establishment of preadipocyte clonal line from epididymal fat pad of ob/ob mouse that responds to insulin and to lipolytic hormones, Proc. Natl. Acad. Sci. U. S. A., 75 (1978) 6054-6058.

[82] P. Verrando, R. Negrel, P. Grimaldi, M. Murphy, G. Ailhaud, Differentiation of ob 17 preadipocytes to adipocytes. Triggering effects of clofenapate and indomethacin, Biochim. Biophys. Acta, 663 (1981) 255265.

[83] R. Negrel, P. Grimaldi, G. Ailhaud, Differentiation of ob 17 preadipocytes to adipocytes. Effects of prostaglandin F2alpha and relationship to prostaglandin synthesis, Biochim. Biophys. Acta, 666 (1981) 15-24.

[84] E. Nikolopoulou, G. Papacleovoulou, F. Jean-Alphonse, G. Grimaldi, M.G. Parker, A.C. Hanyaloglu, M. Christian, Arachidonic acid-dependent gene regulation during preadipocyte differentiation controls adipocyte potential, J. Lipid Res., 55 (2014) 2479-2490.

[85] J. Aubert, P. Saint-Marc, N. Belmonte, C. Dani, R. Negrel, G. Ailhaud, Prostacyclin IP receptor upregulates the early expression of C/EBPbeta and C/EBPdelta in preadipose cells, Mol. Cell. Endocrinol., 160 (2000) 149-156. 
[86] G. Vassaux, D. Gaillard, G. Ailhaud, R. Negrel, Prostacyclin is a specific effector of adipose cell differentiation. Its dual role as a cAMP- and $\mathrm{Ca}(2+)$-elevating agent, J. Biol. Chem., 267 (1992) 1109211097.

[87] P. Saint-Marc, L.P. Kozak, G. Ailhaud, C. Darimont, R. Negrel, Angiotensin II as a trophic factor of white adipose tissue: stimulation of adipose cell formation, Endocrinology, 142 (2001) 487-492.

[88] B. Jia, L. Madsen, R.K. Petersen, N. Techer, R. Kopperud, T. Ma, S.O. Doskeland, G. Ailhaud, J. Wang, E.Z. Amri, K. Kristiansen, Activation of protein kinase a and exchange protein directly activated by cAMP promotes adipocyte differentiation of human mesenchymal stem cells, PLoS One, 7 (2012) e34114.

[89] Y.H. Lee, S.N. Kim, H.J. Kwon, K.R. Maddipati, J.G. Granneman, Adipogenic role of alternatively activated macrophages in beta-adrenergic remodeling of white adipose tissue, Am. J. Physiol. Regul. Integr. Comp. Physiol., 310 (2016) R55-65.

[90] S. Kringelholt, U. Simonsen, T. Bek, Dual effect of prostaglandins on isolated intraocular porcine ciliary arteries, Acta Ophthalmol, 91 (2013) 498-504.

[91] J.D. Borglum, S.B. Pedersen, G. Ailhaud, R. Negrel, B. Richelsen, Differential expression of prostaglandin receptor mRNAs during adipose cell differentiation, Prostaglandins Other Lipid Mediat., 57 (1999) 305-317.

[92] G. Vassaux, D. Gaillard, C. Darimont, G. Ailhaud, R. Negrel, Differential response of preadipocytes and adipocytes to prostacyclin and prostaglandin E2: physiological implications, Endocrinology, 131 (1992) 2393-2398.

[93] V. Garcia-Alonso, C. Lopez-Vicario, E. Titos, E. Moran-Salvador, A. Gonzalez-Periz, B. Rius, M. Parrizas, O. Werz, V. Arroyo, J. Claria, Coordinate Functional Regulation between Microsomal Prostaglandin E Synthase-1 (mPGES-1) and Peroxisome Proliferator-activated Receptor gamma (PPARgamma) in the Conversion of White-to-brown Adipocytes, J. Biol. Chem., 288 (2013) 28230-28242.

[94] P.R. Devchand, A.K. Hihi, M. Perroud, W.D. Schleuning, B.M. Spiegelman, W. Wahli, Chemical probes that differentially modulate peroxisome proliferator-activated receptor alpha and BLTR, nuclear and cell surface receptors for leukotriene B(4), J. Biol. Chem., 274 (1999) 23341-23348.

[95] L. Madsen, R.K. Petersen, M.B. Sorensen, C. Jorgensen, P. Hallenborg, L. Pridal, J. Fleckner, E.Z. Amri, P. Krieg, G. Furstenberger, R.K. Berge, K. Kristiansen, Adipocyte differentiation of 3T3-L1 preadipocytes is dependent on lipoxygenase activity during the initial stages of the differentiation process, Biochem. J., 375 (2003) 539-549.

[96] L. Madsen, L.M. Pedersen, B. Liaset, T. Ma, R.K. Petersen, S. van den Berg, J. Pan, K. Muller-Decker, E.D. Dulsner, R. Kleemann, T. Kooistra, S.O. Doskeland, K. Kristiansen, cAMP-dependent signaling regulates the adipogenic effect of n-6 polyunsaturated fatty acids, J. Biol. Chem., 283 (2008) 7196-7205.

[97] R.K. Petersen, C. Jorgensen, A.C. Rustan, L. Froyland, K. Muller-Decker, G. Furstenberger, R.K. Berge, K. Kristiansen, L. Madsen, Arachidonic acid-dependent inhibition of adipocyte differentiation requires PKA activity and is associated with sustained expression of cyclooxygenases, J. Lipid Res., 16 (2003) 16.

[98] L.A. Carlson, H. Micheli, Effect of prostaglandin E1 on fat mobilizing lipolysis in rat adipose tissue in relation to the nutritional condition, Acta Physiol. Scand., 80 (1970) 289-294.

[99] K. Chatzipanteli, S. Rudolph, L. Axelrod, Coordinate control of lipolysis by prostaglandin E2 and prostacyclin in rat adipose tissue, Diabetes, 41 (1992) 927-935.

[100] B. Richelsen, Relationship between binding and action of different prostaglandins in rat adipocytes with special reference to PGE2 and PGI2, Biochem. Pharmacol., 36 (1987) 4017-4020.

[101] M.S. Draman, F. Grennan-Jones, L. Zhang, P.N. Taylor, T.K. Tun, J. McDermott, P. Moriarty, D. Morris, C. Lane, S. Sreenan, C. Dayan, M. Ludgate, Effects of prostaglandin F(2alpha) on adipocyte biology relevant to graves' orbitopathy, Thyroid, 23 (2013) 1600-1608.

[102] M. Bordicchia, D. Liu, E.Z. Amri, G. Ailhaud, P. Dessi-Fulgheri, C. Zhang, N. Takahashi, R. Sarzani, S. Collins, Cardiac natriuretic peptides act via p38 MAPK to induce the brown fat thermogenic program in mouse and human adipocytes, J. Clin. Invest., 122 (2012) 1022-1036. 
[103] R.M. Gaion, M. Trento, L. Murari, P. Dorigo, C. Ferro, G. Fassina, Prostacyclin and lipolysis in rat fat cells, Biochem. Pharmacol., 33 (1984) 3793-3798.

[104] K. Jaworski, M. Ahmadian, R.E. Duncan, E. Sarkadi-Nagy, K.A. Varady, M.K. Hellerstein, H.Y. Lee, V.T. Samuel, G.I. Shulman, K.H. Kim, S. de Val, C. Kang, H.S. Sul, AdPLA ablation increases lipolysis and prevents obesity induced by high-fat feeding or leptin deficiency, Nat. Med., 15 (2009) 159-168.

[105] M.K. Mater, D. Pan, W.G. Bergen, D.B. Jump, Arachidonic acid inhibits lipogenic gene expression in 3T3-L1 adipocytes through a prostanoid pathway, J. Lipid Res., 39 (1998) 1327-1334.

[106] M.S. Hossain, A.A. Chowdhury, M.S. Rahman, K. Nishimura, M. Jisaka, T. Nagaya, F. Shono, K. Yokota, Development of enzyme-linked immunosorbent assay for Delta12-prostaglandin $\mathrm{J} 2$ and its application to the measurement of the endogenous product generated by cultured adipocytes during the maturation phase, Prostaglandins Other Lipid Mediat., 94 (2011) 73-80.

[107] M.A. Mazid, A.A. Chowdhury, K. Nagao, K. Nishimura, M. Jisaka, T. Nagaya, K. Yokota, Endogenous 15-deoxy-Delta(12,14)-prostaglandin J(2) synthesized by adipocytes during maturation phase contributes to upregulation of fat storage, FEBS Lett., 580 (2006) 6885-6890.

[108] E. Titos, J. Claria, Omega-3-derived mediators counteract obesity-induced adipose tissue inflammation, Prostaglandins Other Lipid Mediat., 107 (2013) 77-84.

[109] G. Chinetti, J.C. Fruchart, B. Staels, Peroxisome proliferator-activated receptors (PPARs): nuclear receptors at the crossroads between lipid metabolism and inflammation, Inflamm. Res., 49 (2000) 497505.

[110] I. Mothe-Satney, C. Filloux, H. Amghar, C. Pons, V. Bourlier, J. Galitzky, P.A. Grimaldi, C.C. Feral, A. Bouloumie, E. Van Obberghen, J.G. Neels, Adipocytes secrete leukotrienes: contribution to obesityassociated inflammation and insulin resistance in mice, Diabetes, 61 (2012) 2311-2319.

[111] J.G. Neels, A role for 5-lipoxygenase products in obesity-associated inflammation and insulin resistance, Adipocyte, 2 (2013) 262-265.

[112] M.R. Peeraully, H. Sievert, M. Bullo, B. Wang, P. Trayhurn, Prostaglandin D2 and J2-series (PGJ2, Delta12-PGJ2) prostaglandins stimulate IL-6 and MCP-1, but inhibit leptin, expression and secretion by 3T3-L1 adipocytes, Pflugers Arch., 453 (2006) 177-187.

[113] J.N. Fain, C.W. Leffler, G.S. Cowan, Jr., C. Buffington, L. Pouncey, S.W. Bahouth, Stimulation of leptin release by arachidonic acid and prostaglandin $E(2)$ in adipose tissue from obese humans, Metabolism, 50 (2001) 921-928.

[114] S. Cinti, UCP1 protein: The molecular hub of adipose organ plasticity, Biochimie, (2016).

[115] R.A. Ghandour, M. Giroud, A. Vegiopoulos, S. Herzig, G. Ailhaud, E.Z. Amri, D.F. Pisani, IP-receptor and PPARs trigger the conversion of human white to brite adipocyte induced by carbaprostacyclin, Biochim. Biophys. Acta, 1861 (2016) 285-293.

[116] A. Vegiopoulos, K. Muller-Decker, D. Strzoda, I. Schmitt, E. Chichelnitskiy, A. Ostertag, M. Berriel Diaz, J. Rozman, M. Hrabe de Angelis, R.M. Nusing, C.W. Meyer, W. Wahli, M. Klingenspor, S. Herzig, Cyclooxygenase-2 controls energy homeostasis in mice by de novo recruitment of brown adipocytes, Science, 328 (2010) 1158-1161.

[117] I. Bayindir, R. Babaeikelishomi, S. Kocanova, I.S. Sousa, S. Lerch, O. Hardt, S. Wild, A. Bosio, K. Bystricky, S. Herzig, A. Vegiopoulos, Transcriptional Pathways in CPGI2-Induced Adipocyte Progenitor Activation for Browning, Front. Endocrinol. (Lausanne), 6 (2015) 129.

[118] L. Madsen, L.M. Pedersen, H.H. Lillefosse, E. Fjaere, I. Bronstad, Q. Hao, R.K. Petersen, P. Hallenborg, T. Ma, R. De Matteis, P. Araujo, J. Mercader, M.L. Bonet, J.B. Hansen, B. Cannon, J. Nedergaard, J. Wang, S. Cinti, P. Voshol, S.O. Doskeland, K. Kristiansen, UCP1 induction during recruitment of brown adipocytes in white adipose tissue is dependent on cyclooxygenase activity, PLoS One, 5 (2010) e11391. 